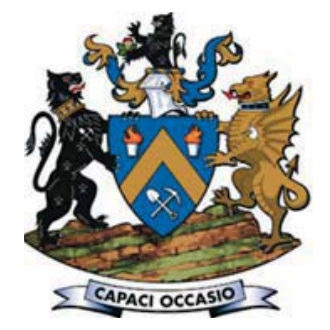

\title{
Progress of brittle microfracturing in crystalline rocks under cyclic loading conditions
}

\author{
by E. Ghazvinian* and M.S. Diederichs`
}

\section{Synopsis}

The stress at onset of yielding for the walls of deep underground excavations in hard rock is significantly less than the laboratory strength of intact rock samples. The wall stability is rather controlled by the microfracturing strength of the rock (i.e. crack propagation (CD) and initiation (CI) thresholds). Factors such as loading and unloading effect of excavation, glaciation, stress rotation in front of a tunnel face, etc. can contribute to the progressive damage of the rock, influencing the $\mathrm{CI}$ and $\mathrm{CD}$ thresholds and therefore contributing to the damage intensity around underground openings. The effect of stress rotation and stress fatigue on crack damage thresholds is systematically investigated in this paper through state-of-the-art laboratory testing and monitoring techniques in combination with advanced grain-based numerical modelling.

Keywords

brittle microfracturing, cyclic loading, crack initiation, crack propagation.

\section{Introduction}

The long-term stress path for the near-field rock surrounding deep underground excavations is typically more complex than simple monotonically increasing deviatoric stress conditions. The state of stress for a point in the wall of an underground opening can go through multiple loading and unloading cycles as the excavation advances and moves past the point. For underground structures such as deep geological repositories (DGRs) with ultra-long design life (e.g. a million years), the stress oscillation can continue after the excavation is completed due to glacial loading/unloading cycles. Microfracturing behaviour of intact rocks can change significantly when they undergo mechanical loading/unloading cycles, in comparison to the crack damage parameters that are measured from the initial state of the rock.

Strength degradation through accumulation of crack damage for brittle rocks was examined in detail by Martin (1993), Eberhardt (1998), and Diederichs (2000) through cyclic testing of the Lac du Bonnet granite. Martin (1993) captured the cohesion loss and mobilization of friction that resulted from accumulation of crack damage within intact brittle rocks through a series of damagecontrolled cyclic tests in which the maximum applied stress was increased in each consecutive load cycle. This was mainly accomplished by the investigation of the critical damage (CD) locus that was defined from the collected strain gauge data. Eberhardt (1998) further advanced the knowledge of the 'fatigue' strength of brittle rocks by using the acoustic emission (AE) technique in addition to the measured strain data collected from damage-controlled cyclic tests whereby samples were loaded beyond $\mathrm{CD}$, below the $\mathrm{CD}$ threshold, or loaded incrementally to reach failure.

The effect of stress fatigue on the crack initiation (CI) and crack propagation (CD) thresholds is further investigated in this paper. The strength degradation and damage accumulation for the pink Lac du Bonnet granite is studied through damage-controlled tests. Monitoring of the loading/unloading cycles with novel techniques such as lateral Pwave velocity $\left(V_{p}\right)$ measurement and the associated discrete element method-based grain-based models (GBMs) provided a useful insight into the mechanics of crack damage accumulation in brittle intact rocks.

\section{UCS testing of the Lac du Bonnet granite}

The pink Lac du Bonnet granite was chosen for investigation in this paper. The previous research and existing literature on this rock type provide a good platform for comparison of the new findings and previous conclusions. Samples of the granite were obtained from the Cold Spring Quarry site in Manitoba, which is a surface exposure of the massive granite found at depth within the AECL's Underground Research Laboratory (URL). The

\footnotetext{
* Itasca Consulting Group, Minneapolis, MN, USA.

+ Queen's University, Kingston, ON, Canada.

(c) The Southern African Institute of Mining and Metallurgy, 2018. ISSN 2225-6253. This paper was first presented at the AfriRock 2017 International Symposium, 30 September 6 October 2017, Cape Town Convention Centre, Cape Town.
} 


\section{Progress of brittle microfracturing in crystalline rocks under cyclic loading conditions}

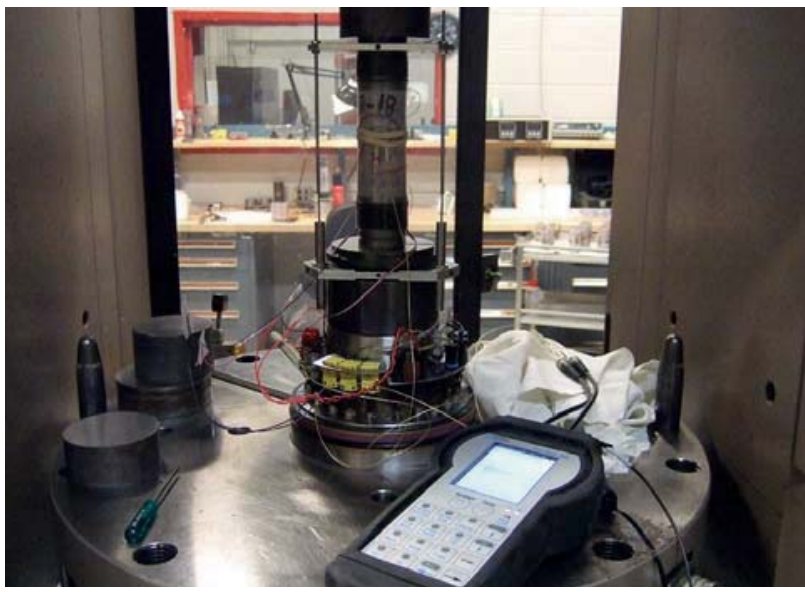

Figure 1-Test set-up for the UCS and cyclic damage-controlled testing of the Lac du Bonnet granite

samples from the quarry contain minimal pre-existing damage in comparison to the grey Lac du Bonnet granite from the $420 \mathrm{~m}$ level or the pink granite from the $240 \mathrm{~m}$ level of the URL (Martin, 1993; Eberhardt, 1998).

In the current work, mechanical properties of the intact pink Lac du Bonnet granite were measured from two UCS tests (on specimens LdB-1 and LdB-2) to establish the base properties for comparison with the damage-controlled experiments. The testing set-up for the Lac du Bonnet granite is shown in Figure 1.

The lower- (CI_L) and upper-bound crack initiation threshold (CI_U) are estimated from the AE data (Ghazvinian, Diederichs, and Martin, 2012). The CD threshold was not evident in the AE data collected for the specimens, therefore the reversal point of volumetric strain was approximated as the crack propagation threshold for the tested samples. The intact mechanical properties of the investigated Lac du Bonnet granite are presented in Table I, and the properties measured in this work are compared with those from the literature. The literature values are taken from Diederichs (2000), where the data available for the pink Lac du Bonnet granite was summarized from documents by Martin (1993), Martin and Stimpson (1994), Martin and Chandler (1994), Eberhardt (1998), Hommand-Etienne, Hoxha, and Shao (1998), Gorski and Yu (1991), Wilkins (1980), Kelly, Peck, and James (1993), and Lajtai (1988).

The difference between the measured CD and UCS in this study and the values from the literature can be attributed to the level of pre-existing damage in the specimens. Other researchers mostly reported the mechanical properties of the Lac du Bonnet granite from the $130 \mathrm{~m}$ level of URL for undamaged rock, while the samples tested for this study were taken from the Cold Spring Quarry.

\section{Damage-controlled testing of the Lac du Bonnet granite}

Two damage-controlled cyclic tests were performed on the Lac du Bonnet granite specimens (LdB-DC1 and LdB-DC2). The specimens were loaded in uniaxial compression up to an axial stress above the $\mathrm{CD}$ threshold for the rock. The specimens were then unloaded, completing one cycle, and then loaded again to an identical axial stress as in the first cycle and then unloaded again. The same routine was repeated until the specimens were loaded up to failure during the last cycle. The loading histories for the two specimens are shown in Figure 2 and the loading conditions are listed in Table II. Interestingly, the load cycling had no significant effect on the peak strength of the Lac du Bonnet granite specimens (listed in Table II and shown in Figure 3) when compared to the values obtained from the UCS tests in this study and those reported in the literature. A similar observation was reported by Martin (1993).

\begin{tabular}{|c|c|c|c|c|}
\hline \multirow{2}{*}{$\begin{array}{l}\text { Mechanical } \\
\text { parameters }\end{array}$} & \multicolumn{3}{|c|}{ Measured properties } & \multirow{2}{*}{$\begin{array}{l}\text { Literature values } \\
\text { (Cold Spring Quarry to URL } 130 \mathrm{~m} \\
\text { level) }\end{array}$} \\
\hline & LdB-1 & LdB-2 & Average & \\
\hline$E(\mathrm{GPa})$ & 71.6 & 71.4 & 71.5 & $65-70$ \\
\hline $\mathrm{v}$ & 0.21 & 0.22 & 0.22 & $0.22-0.26$ \\
\hline UCS (MPa) & 257.6 & 265.9 & 261.8 & $200-230$ \\
\hline Cl_L (MPa) & 63.7 & 68.8 & 66.3 & $\begin{array}{l}72 \text { (AE) - (Hommand et al., 1995) } \\
71 \text { - (Duevel and Haimson, 1997) } \\
75 \text { - (Read, 1994) } \\
80 \text { - (Diederichs, 2000) } \\
81 \text { (AE) - (Eberhardt, 1998) }\end{array}$ \\
\hline $\mathrm{Cl} \_\mathrm{U}(\mathrm{MPa})$ & 93.4 & 98.2 & 95.8 & $\begin{array}{l}95-\text { (Duevel and Haimson, 1997) } \\
100-\text { (Read, 1994) } \\
93-\text { (Diederichs, 2000) } \\
104 \text { (AE) - (Eberhardt, 1998) }\end{array}$ \\
\hline $\mathrm{CD}(\mathrm{MPa})$ & 207.9 & 215.4 & 211.7 & 156 - (Eberhardt, 1998) \\
\hline
\end{tabular}


Progress of brittle microfracturing in crystalline rocks under cyclic loading conditions
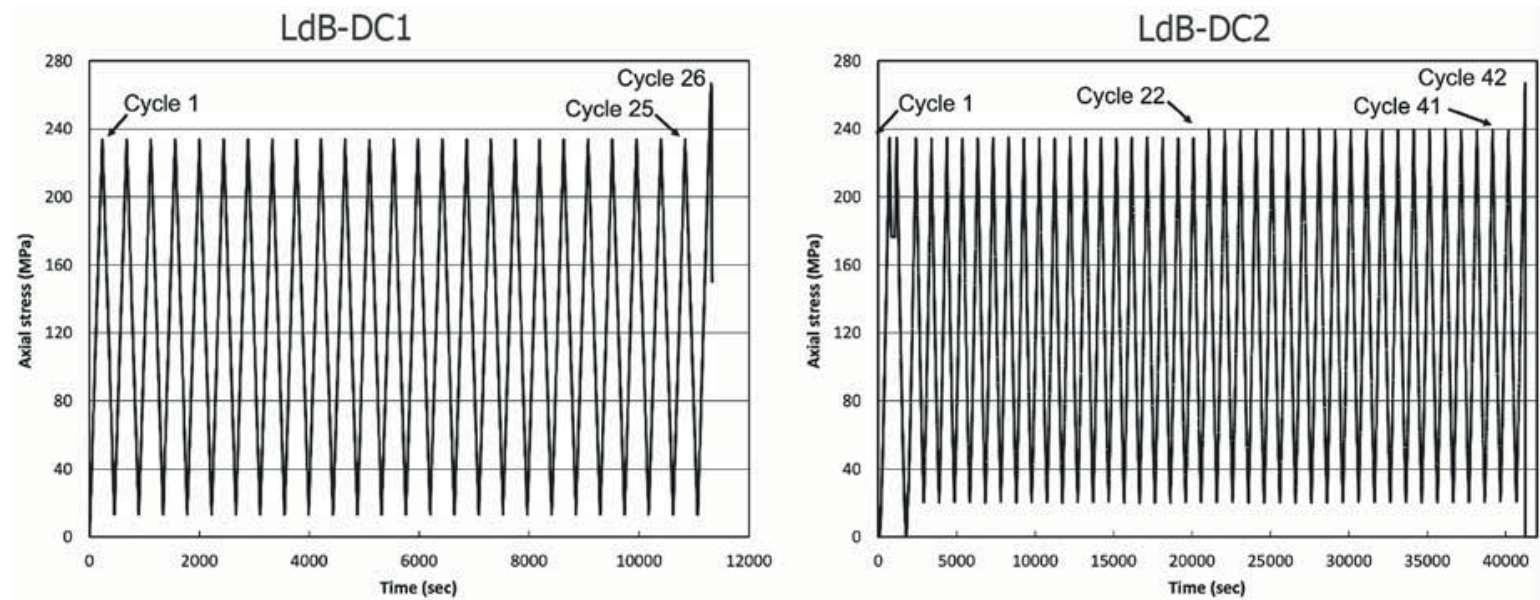

Figure 2-Axial stress versus time for the cyclic damage-controlled tests performed on the LdB-DC1 and LdB-DC2 specimens

\begin{tabular}{|c|c|c|}
\hline \multicolumn{3}{|c|}{$\begin{array}{l}\text { Table II } \\
\text { Mechanical properties and cyclic loading conditions for the Lac du } \\
\text { Bonnet granite specimens }\end{array}$} \\
\hline Mechanical parameters & LdB-DC1 & LdB-DC2 \\
\hline Peak strength at the final cycle (MPa) & 266.6 & 267.3 \\
\hline$E-$ first cycle (GPa) & 68.8 & 67.8 \\
\hline$v$ - first cycle & 0.21 & 0.19 \\
\hline Number of cycles & 25 & 41 \\
\hline Loading stress (MPa) & Approx. 234 & $\begin{array}{c}235 \text { (cycles } 1-21) \\
240 \text { (cycles 22-41) }\end{array}$ \\
\hline Unloading stress (MPa) & Approx. 13 & 20 \\
\hline
\end{tabular}

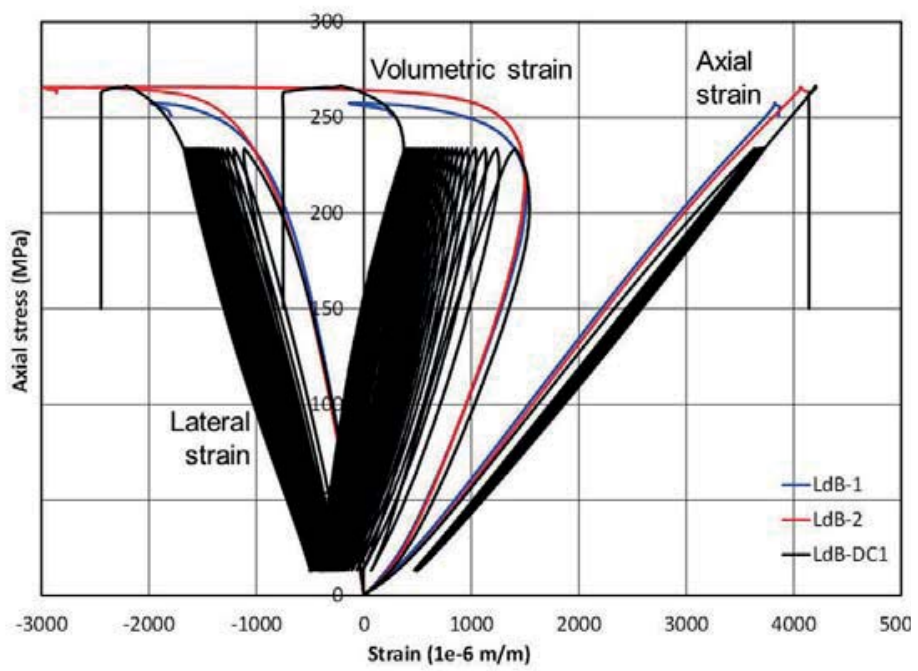

Figure 3-Comparison of the mechanical behaviour of the Lac du Bonnet granite samples tested in monotonically increasing compressional load and in cyclic damage-controlled loading conditions

For accurate estimation of crack volumetric strain, the elastic constants for each loading and unloading increment of each cycle were calculated independently over a range between 30 and $80 \mathrm{MPa}$ to minimize the effect of crack closure and formation of new fractures on the calculated elastic parameters. The calculated elastic constants for sample
LdB-DC1 are shown in Figure 4. The Young's modulus suddenly increases from cycle 1 to cycle 2 ; this could be the result of crack closure in cycle 1 , which was not repeated in the following cycles since the minimum unloading stress (13 $\mathrm{MPa}$ ) did not allow for the fractures to open as a result of relaxation. According to Eberhardt (1998), collapse of 


\section{Progress of brittle microfracturing in crystalline rocks under cyclic loading conditions}

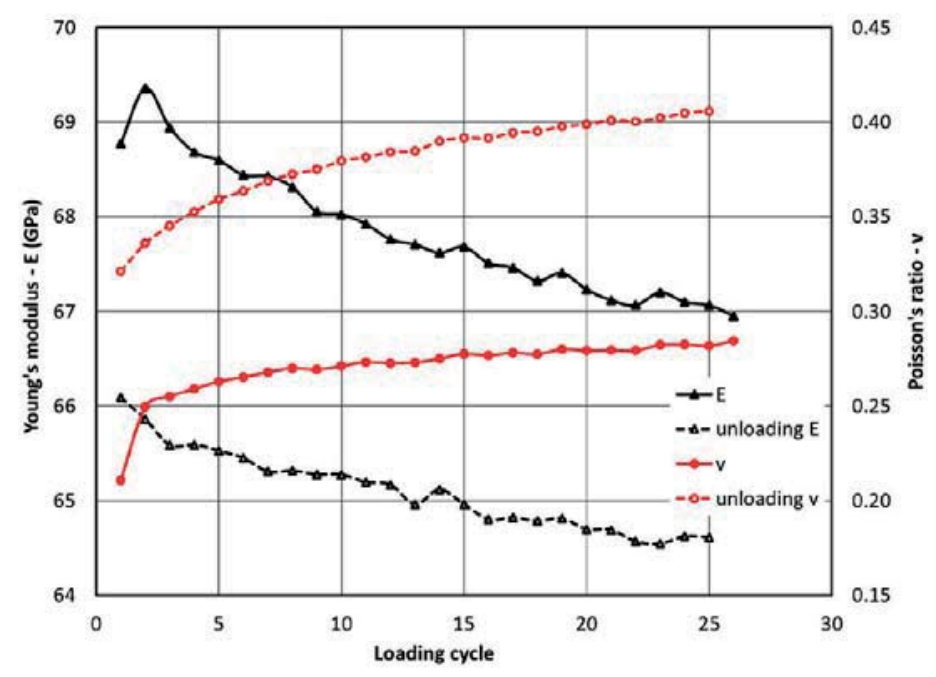

Figure 4-The elastic constants calculated for the loading and unloading increments of each loading cycle for LdB-DC1

bridging material between cracks could be a stiffening mechanism for the intact rock and another reason for the sudden increase in the Young's modulus. The major collapse of bridging material occurs in the first cycle after surpassing the $\mathrm{CD}$ threshold, therefore this effect cannot be observed in the unloading Young's modulus and the Young's moduli of following cycles. An abrupt increase in the Poisson's ratio is also observed between cycles 1 and 2, while the changes after cycle 2 are gradual. This sudden increase is attributed to the formation of a large population of extensile fractures in the first cycle after the axial stress in the rock passes the $\mathrm{CI}$ threshold. In general, a gradual reduction in the moduli of the rock as a function of accumulation of damage concurrent with gradual increase in the Poisson's ratio is observed for the Lac du Bonnet sample with increasing loading cycles.

The Cl threshold, axial stress associated with the maximum crack volumetric strain, according to Martin (1993), for each cycle for the LdB-DC1 specimens is marked in Figure 5 with red circles and the CI locus is shown with the red line. It can be seen in this figure that if the crack volumetric strain is accepted as an indicator of the $\mathrm{CI}$ threshold, then the CI locus remains constant with each loading-unloading cycle. The same behaviour is reported by Martin (1993), who concluded that the CI threshold is independent of damage accumulated in the sample.

Investigation of the AE data collected from the damagecontrolled testing of LdB-DC1 (Figure 6a) shows that the AE events at the $\mathrm{CI}$ threshold and between the $\mathrm{CI}$ and $\mathrm{CD}$ thresholds occur only during the first loading cycle and the $\mathrm{AE}$ activity of the sample at the $\mathrm{CI}$ threshold diminishes after the first cycle. From cycle 2 onward, the sample is acoustically active only at the $\mathrm{CD}$ threshold and stresses above this threshold. This is also in agreement with the findings of Eberhardt (1998), in which the so-called CI threshold estimated from the AE method in damagecontrolled test for cycles 2 onward is within a very close

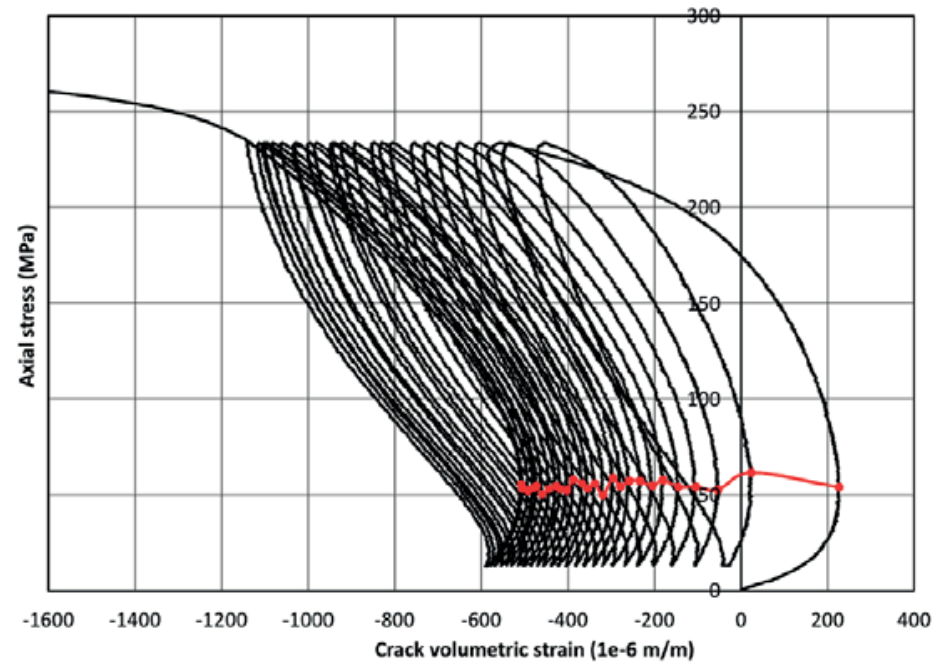

Figure 5-Crack volumetric strain for the specimen LdB-DC1; the maximum crack volumetric strains from the loading part of each cycle are connected with the red line 


\section{Progress of brittle microfracturing in crystalline rocks under cyclic loading conditions}

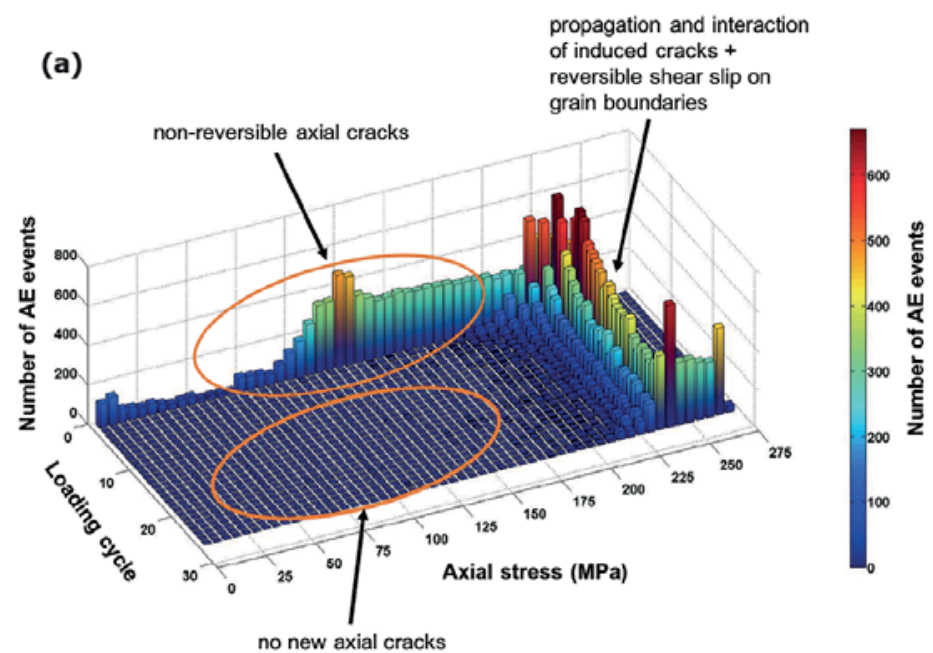

(b)

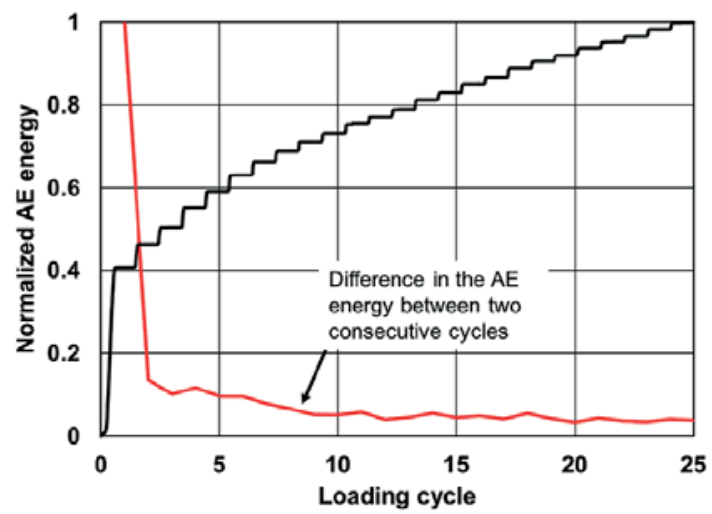

Figure $6-A E$ results for LdB-DC1. (a) Histogram of AE events that occurred during each cycle, and (b) normalized cumulative AE energy that has been dissipated by the rock in each cycle of the damage-controlled test

range to the $\mathrm{CD}$ stress level. A look at the energy associated with the AE events for LdB-DC1 (Figure 6b), calculated according to Pollock (2012), shows that most of the energy dissipated by microfracturing during the test occurs in the first cycle. Considering that all of the AE events after cycle 1 occur at the CD threshold and higher stresses, they are mainly associated with the coalescence of the local fractures and development of existing fractures. The amount of energy that is released by the specimen after cycle 1 gradually decreases with increasing number of loading cycles. This decrease in release of energy is also observed in the form of a decline in the number of AE events as a function of loading cycles. This demonstrates that the formation and/or the extension of a microcrack network within the intact rock requires more energy (higher axial stress) for further extension and interaction of the existing microcracks.

The AE data contradicts the notion that the CI threshold, as estimated from the reversal of crack volumetric strain, is independent of the damage accumulated in the sample as suggested by Martin (1993). It can be realized from the AE data (release of the majority of the AE energy at the $\mathrm{CI}$ threshold in the first cycle), and also the sudden increase of the Poisson's ratio between cycles 1 and 2, that the $\mathrm{CI}$ threshold and the notion of crack initiation, in a given orientation, occurs only once for a rock specimen.
A study of the accumulation of shear and tensile microcracks during the first six loading cycles of specimen LdB-DC2 (Figure 7a) and the entire duration of the test (Figure $7 \mathrm{~b}$ ) reveals that the majority of the tensile events occur in the first cycle. However, the accumulation of sheardominated events that mostly occur around the CD threshold after cycle 1 continues to evolve until complete failure. This can be attributed to the fact that the fractures forming the $\mathrm{CI}$ threshold are mostly tensile, while the CD threshold in rocks is controlled by the shear fractures that allow coalescence and formation of transgranular bridges. Interaction and coalescence of microfractures play a significant role in controlling the short-term strength of brittle rocks.

\section{Numerical replication of progressive damage in the Lac du Bonnet granite}

A suite of laboratory test data for the pink Lac du Bonnet granite was evaluated and discussed in the previous section. In order to further examine the conclusions based on the laboratory test data, a 3D Voronoi grain-based model (GBM) was set up to replicate the mechanical behaviour of the Lac $\mathrm{du}$ Bonnet granite numerically. The findings in the previous section can be summarized in two major points:

> Formation of the majority of the microcracks at the crack initiation threshold occurs the first time this limit 


\section{Progress of brittle microfracturing in crystalline rocks under cyclic loading conditions}
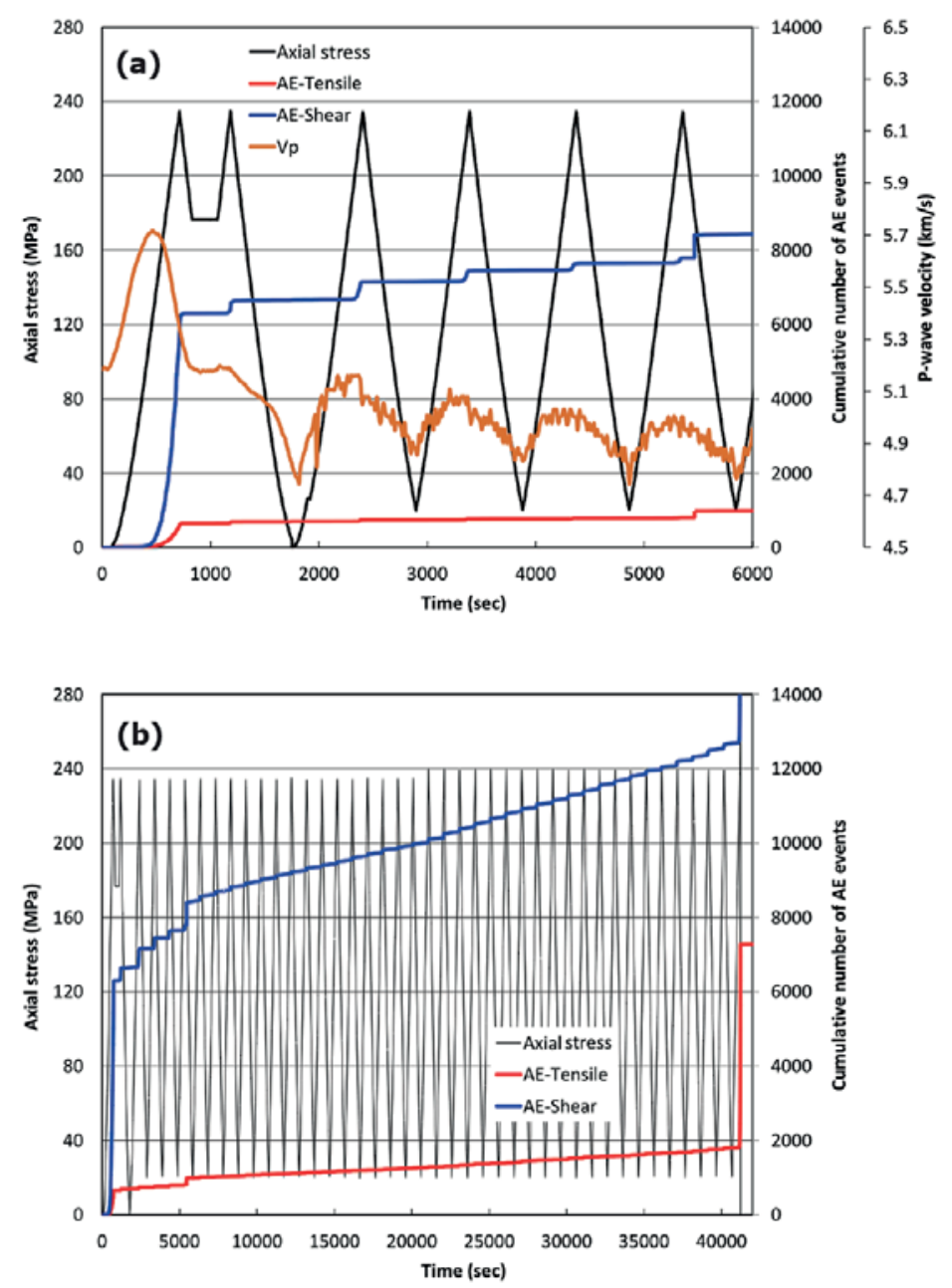

Figure 7 - (a) Accumulation of acoustically captured shear- and tensile-dominated fractures and the associated lateral P-wave velocity during the first six loading cycles for LdB-DC2, and (b) accumulation of acoustically captured shear and tensile fractures during the damage-controlled testing of LdB-DC2

is surpassed and further crossing of this limit, for instance through stress cycling, is not critical to the crack density within the rock (in other words the $\mathrm{CI}$ threshold for a rock only occurs once in a given orientation).

> Initiation of the dominant microcracks at the $\mathrm{CI}$ threshold is mostly extensile while the propagation, bridging, and coalescence of the fractures at the $\mathrm{CD}$ limit occur mainly in shear.

The Lac du Bonnet granite 3D GBM provides a controlled test environment that the assumptions about the mechanical behaviour of the rock can be tested against, within the limits of the model.

\section{Specimen generation, numerical set-up, and calibrated properties}

A cylindrical specimen was generated in Neper (Quey, Dawson, and Barbe, 2011; Ghazvinian, Diederichs, and Quey, 2014) with radius of $50 \mathrm{~mm}$ and length of $125 \mathrm{~mm}$ (Figure $8 \mathrm{a}$ ). The cylindrical vessel was filled with 5000 Voronoi grains, each zoned with tetrahedral elements with an average edge length of $1 \mathrm{~mm}$. The grain size was chosen to be consistent with the representative volume element (Ghazvinian, Diederichs, and Quey, 2014) to minimize its effect on the model response. The model micro-parameters were calibrated in an iterative process following the method described in Ghazvinian, Diederichs, and Quey (2014). Elastic behaviour was assumed for the grains, and failure within the model was allowed only along the grain contacts. The elastic properties of the grains were taken from Lama and Vutukuri (1978) to approximately represent the minerals composing the Lac du Bonnet granite. To have a better control on the damage thresholds, a distribution of one standard deviation was introduced for the cohesion and tensile strength at the contacts; this also required calibration according to $\mathrm{CI}$ and $\mathrm{CD}$ thresholds. This distribution was applied to the contacts randomly using a normal distribution. The calibrated micro-parameters and the corresponding model macro-response are listed in Table III. The stress-strain behaviour of the calibrated UCS model for the Lac du Bonnet granite is shown in Figure 8b.

\section{UCS model}

In the grain-based model developed for the Lac du Bonnet granite, the orientation of normal vectors to the surface of the 


\section{Progress of brittle microfracturing in crystalline rocks under cyclic loading conditions}

(a)

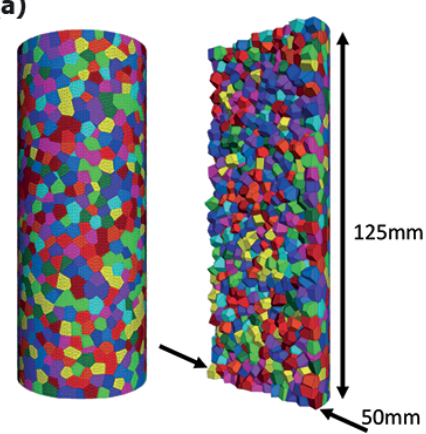

(b)

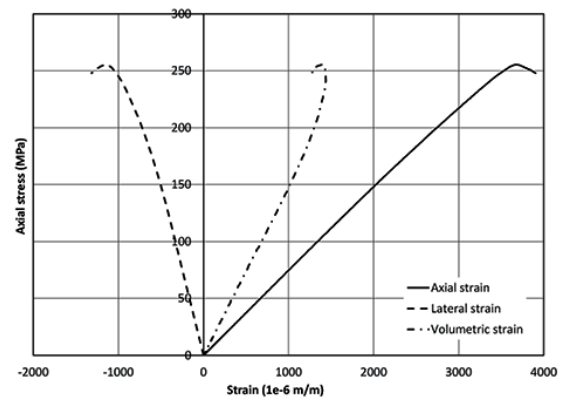

Figure 8 - (a) 3D GBM specimen, including 5000 grains, (b) stress-strain curves for the UCS model calibrated to the Lac du Bonnet granite properties

\begin{tabular}{|c|c|c|c|}
\hline \multicolumn{2}{|l|}{ Model micro-parameters } & \multicolumn{2}{|c|}{ Model macro-properties } \\
\hline Contact normal stiffness $k_{n}(\mathrm{GPa} / \mathrm{m})$ & 68000 & UCS (MPa) & 255.5 \\
\hline Contact normal to shear stiffness ratio $k_{n} / k_{s}$ & 5 & $\mathrm{Cl}(\mathrm{MPa})$ & 64 \\
\hline Contact peak cohesion $c_{p}(\mathrm{MPa})$ & $120( \pm 10)^{\star}$ & $\mathrm{CD}(\mathrm{MPa})$ & 235 \\
\hline Contact residual cohesion $c_{r}(\mathrm{MPa})$ & 0 & $E(\mathrm{GPa})$ & 74.8 \\
\hline Contact peak tensile strength $T_{p}(\mathrm{MPa})$ & $90( \pm 5)^{*}$ & v & 0.25 \\
\hline Contact residual tensile strength $T_{r}(\mathrm{MPa})$ & 0 & & \\
\hline Contact peak friction angle $\Phi_{\mathrm{p}}\left({ }^{\circ}\right)$ & 0 & & \\
\hline Contact residual friction angle $\phi_{\mathrm{r}}\left(^{\circ}\right)$ & 20 & & \\
\hline Grain Young's modulus E (GPa) & 150 & & \\
\hline Grain Poisson's ratio v & 0.28 & & \\
\hline
\end{tabular}

*Values in parentheses are the one standard deviation for the contact strength components that were assigned to contacts with a uniform distribution.

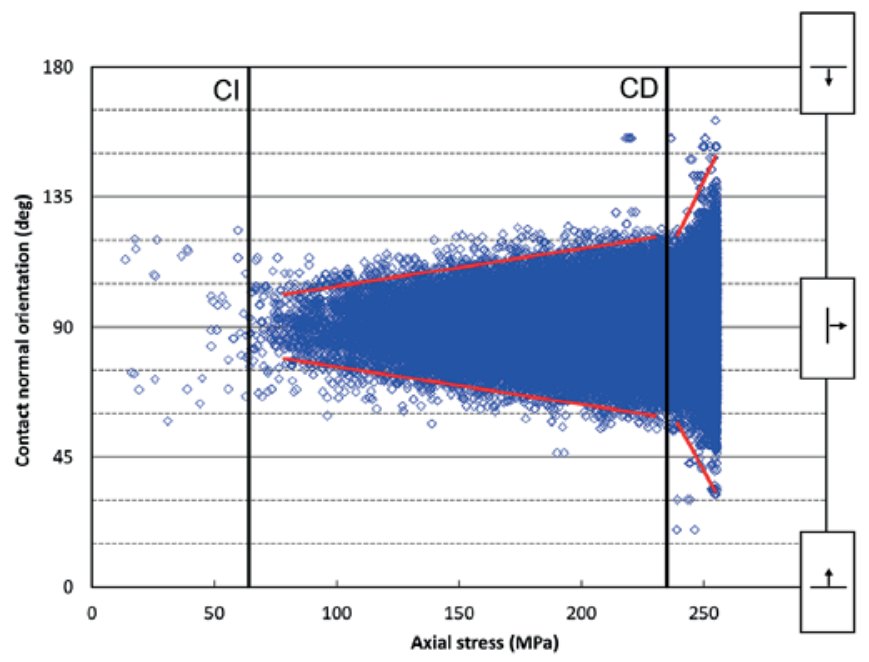

Figure 9-Orientation of normal vectors for sub-contacts failed in tension for the LdB granite UCS model

sub-contacts which failed in tension was recorded with respect to the orientation of the loading axis. Sub-contacts with surface-normal angles equal to $90^{\circ}$ are perfectly aligned with the direction of applied load. With the change of a subcontact normal angle from $90^{\circ}$, the sub-contact surface first becomes sub-parallel to the loading direction and with further changes, at extreme limits (normals equal to $0^{\circ}$ or $180^{\circ}$ ) it becomes perpendicular to the direction of loading.
The progress of damage and the orientation of normal vectors for sub-contacts which failed in tension for the Lac du Bonnet UCS model are shown in Figure 9. The CI and CD thresholds are also overlain on this figure. It is interesting to note in this figure that the most critical cracks in the model are aligned parallel to sub-parallel to the direction of loading. The sub-contacts with normals within a range of $75^{\circ}$ to $105^{\circ}$ are those that fail first. The range for the normal of the less 


\section{Progress of brittle microfracturing in crystalline rocks under cyclic loading conditions}

critical sub-contacts grows to $60^{\circ}-120^{\circ}$ immediately before the onset of CD threshold. As soon as the CD threshold is crossed, the sub-contacts with normals within the range of $30^{\circ}-150^{\circ}$ become unstable and fail.

\section{Damage-controlled models}

Damage-controlled numerical simulations were performed on the Lac du Bonnet granite grain-based model through load cycling, similar to the cyclic tests performed in the laboratory. Three tests were simulated with different limits for maximum applied stress in each cycle. Model DC-140 was loaded up to $140 \mathrm{MPa}$ (above CI and below CD), model DC-200 was loaded up to $200 \mathrm{MPa}$ (slightly below CD), and model DC-240 was loaded up to $240 \mathrm{MPa}$ (above CD) in each cycle (Figure 10).

The unloading stress limit for all the models was set to 15 $\mathrm{MPa}$. Due to the existing hysteresis in the models (timestepping is needed to notice the effect of change in applied stress in the middle of the specimen), usually a $10 \mathrm{MPa}$ overshooting was observed in loading and approximately 2 MPa overshooting when switching between unloading to loading. The axial stress cycling for the models versus timesteps and the corresponding stress-strain behaviour are shown in Figure 10. Models DC-140 and DC-200 were cycled six times and then were loaded up to failure in cycle 7 . Model
DC-240 was cycled four times, and upon completion of cycle 4 (unloading) it had failed and could not be loaded up again.

Similar to the laboratory testing results, the stress cycling for models DC-140 and DC-200 had no influence on the peak strength of the models. These models failed at approximately $255 \mathrm{MPa}$ in cycle 7 , at a stress similar to the UCS model in the previous section. The DC-240 model that was cycled to a stress (just under $250 \mathrm{MPa}$ ) close to the UCS for this model $(255.5 \mathrm{MPa})$ experienced a drop in the peak strength. The study of the stress-strain curves for the damage-controlled models shows that as the cycling stress limit is increased, the permanent damage that is represented in the deformational behaviour of the models (softening) is more distinct.

To further investigate the dominance of tensile fractures at the $\mathrm{CI}$ threshold, the progressive damage in the damagecontrolled models is shown in Figure 11, presenting the orientation of normal vectors to the sub-contacts failed in tension. The ranges for normal vector orientation for the most critical sub-contacts from the UCS model (Figure 9) are shown in Figure 11 with dashed red lines. The major accumulation of failure of critical sub-contacts (normal vectors between $75^{\circ}$ and $105^{\circ}$ ) occurs in the first cycle for all of the cyclic models. In DC-140 and DC-200, where the CD is not surpassed during stress cycling, the steeper sub-contacts (less critical) with normal vectors mainly ranging between
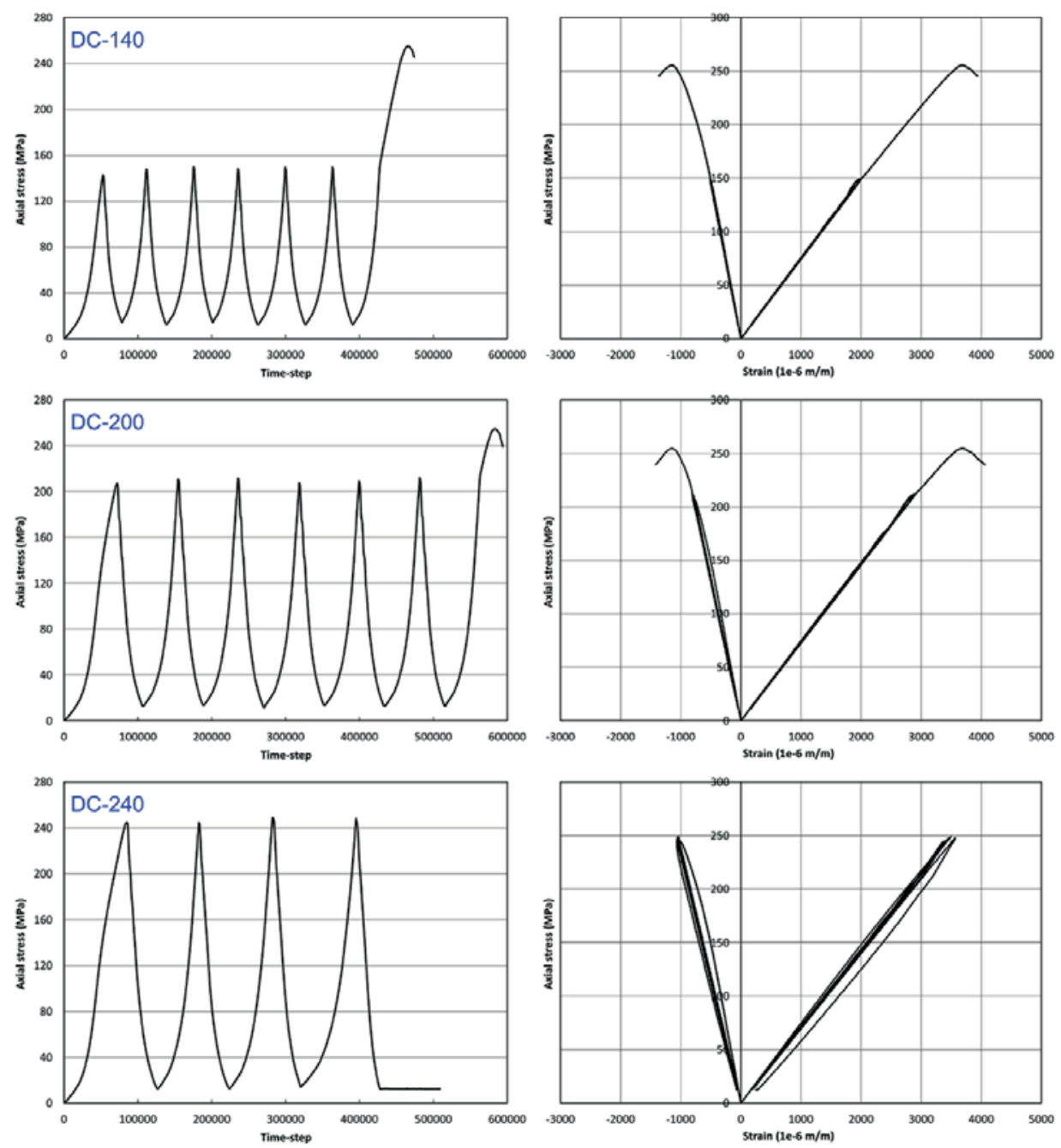

Figure 10-Axial stress versus time-step and the associated stress-strain behaviour for damage-controlled models DC-140, DC-200, and DC-240 


\section{Progress of brittle microfracturing in crystalline rocks under cyclic loading conditions}

$15^{\circ}$ and $165^{\circ}$ start to fail after crossing the CD threshold limit in the last loading increment where the models are taken to complete failure. In the DC-240 model, for which the measured stress in the model goes beyond the $\mathrm{CD}$ threshold in the first cycle, the range for sub-contact normals that fail in each cycle grows larger with each consecutive cycle, and in the final cycle (cycle 4) sub-contacts with normal vectors as steep as approximately $0^{\circ}$ or $180^{\circ}$ are observed to fail. It appears from the comparison of the plots and the range of contact-normal orientations in Figure 11 that the extent of damage and the maximum stress threshold that a rock has experienced in the past play a key role in exciting isolated microcracks, or the least-critical grain boundaries, to mobilize.
Unloading damage in the form of sub-contact failure is observed to happen at the unloading increment of cycle 1 only for models DC-140 and DC-200. For DC-240, the unloading damage is observed to occur at all cycles and it becomes more severe with each loading cycle. In Figure 11, the unloading damage for DC-140 and DC-200 in cycle 1 appears to be mostly due to the failure of sub-vertical critical sub-contacts (normal vectors between $75^{\circ}$ and $105^{\circ}$ ). However, the arched shape of each loading cycle for DC-240 in Figure 10 indicates that the unloading damage is due to failure of sub-contacts with steep normal vectors. Based on previous discussions, this could represent bridging and coalescing shear microcracks in a laboratory sample.
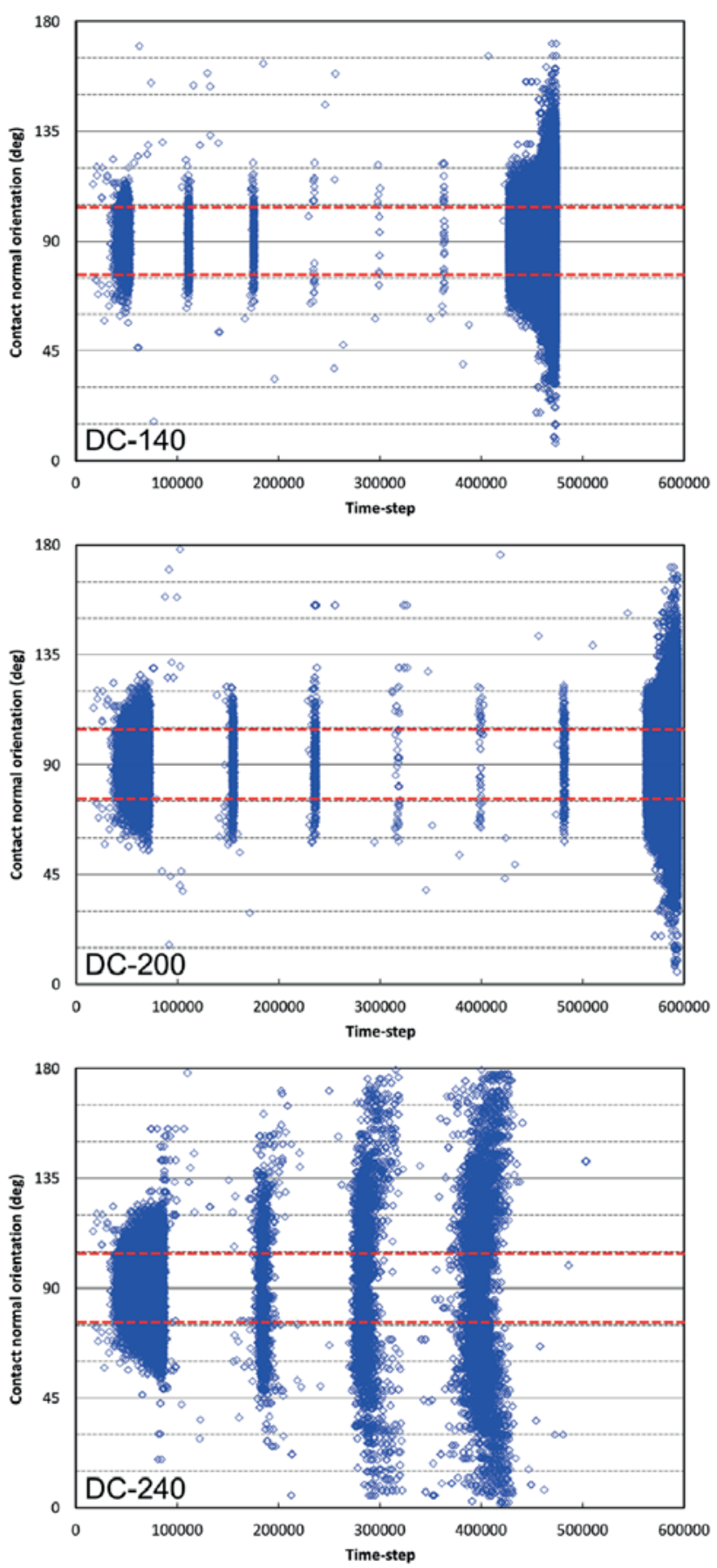


\section{Progress of brittle microfracturing in crystalline rocks under cyclic loading conditions}

\section{Conclusions}

The concept of stress fatigue and its effect on crack initiation and crack propagation thresholds for brittle rocks was investigated. Accumulation of damage and subsequent degradation of strength was studied for the pink Lac du Bonnet granite from the Cold Spring Quarry in Manitoba, Canada through laboratory damage-controlled cyclic tests. The associated discontinuum simulations by means of 3D Voronoi grain-based models proved to be significantly helpful in developing a better understanding of the mechanisms of damage at $\mathrm{CI}$ and $\mathrm{CD}$ thresholds.

The peak strength of the Lac du Bonnet granite appeared to be unaffected by the stress fatigue (loaded beyond the CD threshold) within the number of cycles (maximum of 41) the samples were tested in this study. However, according to one of the damage-controlled grain-based models, if the maximum stress in each cycle is close to the UCS value, a drop in the peak strength may be observed. It should be noted that damage-controlled testing is a lengthy process, and therefore a fast loading rate is usually employed. It can be speculated that with decreasing loading rates, the mobilized microfractures will have the chance to propagate and possibly degrade the strength of the rock with increasing loading cycles.

The crack propagation threshold (CD) for the Lac du Bonnet granite appeared to gradually increase with each loading cycle when the sample is loaded beyond the CD threshold in each cycle. This behaviour was observed in both the strain (stress associated with the reversal of volumetric strain) and the AE data. The decay in the number of $\mathrm{AE}$ events and reduction in the dissipated AE energy with increasing loading cycles suggests a slowing in the rate of propagation of mobilized fractures and the need for higher energy in the form of increased axial stress for further propagation. This explains the increase in $\mathrm{CD}$ threshold with each loading cycle. The study by Eberhardt (1998), however, showed that if the cycling continues after the gradual increase in CD threshold, it would start to decline eventually.

Interesting results from the $\mathrm{AE}$ monitoring, which had the capability to distinguish between the shear and tensile events for a damage-controlled test on the Lac du Bonnet granite, and the numerical models proved that the crack initiation threshold (CI) for a rock occurs only once, the first time this threshold is crossed. While this can also be detected by a sudden jump in Poisson's ratio from the first cycle to the second, crack volumetric strain appeared not to be sensitive enough and accordingly estimated a similar $\mathrm{CI}$ for all the loading cycles of a damage-controlled test.

The AE results from the laboratory tests and damagecontrolled grain-based numerical simulations indicate that the majority of the critical links within an intact brittle rock, which are commonly either perfectly aligned or are subparallel to the direction of major principal stress, dilate in an extensile mode when the $\mathrm{CI}$ threshold is reached. Therefore no other critical extensile weak links are left undilated within the intact rock to mobilize the next time this threshold is crossed within a loading-unloading condition. Conversely, the propagation, coalescence, and bridging of existing fractures that define the $\mathrm{CD}$ threshold and commonly have a shear mechanism, continue to grow and involve microfracture paths with steeper orientations with respect to the orientation of major principal stress with each cycle.

\section{Acknowledgements}

The authors would like to acknowledge the Nuclear Waste Management Organization of Canada (NWMO) and the National Science and Engineering Research Council of Canada (NSERC) for supporting this research. Special thanks to Denis Labrie from CanmetMINING, Natural Resources Canada, as well as Tobias Backers and Tobias Meier of geomecon $\mathrm{GmbH}$ for providing access to high-quality laboratory testing and insightful discussions.

\section{References}

DiEDERICHS, M.S. 2000. Instability of hard rock masses: the role of tensile damage and relaxation. PhD thesis, University of Waterloo, Waterloo, Ontario.

Duevel, B. and Haimson, B. 1997. Mechanical characterization of pink Lac du Bonnet Granite: Evidence of nonlinearity and anisotropy. International Journal of Rock Mechanics and Mining Sciences and Geomechanics Abstracts, vol. 34, no. 3-4. Paper no. 117.

EBERHARDT, E. 1998. Brittle rock fracture and progressive damage in uniaxial compression. PhD thesis, Department of Geological Sciences, University of Saskatchewan, Saskatoon. 334 pp.

Ghazvinian, E. Diederichs, M.S., and Martin, C.D. 2012. Identification of crack damage thresholds in crystalline rock. Proceedings of Eurock 2012, Stockholm, Sweden. International Society for Rock Mechanics, Lisbon, Portugal.

GHAZvinian, E. Diederichs, M.S., and QueY, R. 2014. 3D random Voronoi grainbased models for simulation of brittle rock damage and fabric-guided micro-fracturing. Journal of Rock Mechanics and Geotechnical Engineering, vol. 6, no. 6. pp. 506-521.

GoRsкi, B. and YU, Y.S. 1991. Tensile strength tests on URL rock samples from Borehole 401-009-HF1. CANMET report MRL 91-080(TR). Natural Resources Canada.

Hommand-Etienne, F. HoxнA, D. and Shao, J.F. 1998. A continuum damage constitutive law for brittle rocks. Computers and Geotechnics, vol. 22, no. 2. pp. 135-151

Hommand, F. Hoxha, D. Shao, J.F. Sibai, M., and Duveau, G. 1995. Endommagement de granites et de marnes: Essais mechaniques, identification des parameters d'un modele d'endommagement et simulation. Final Report B RP O.ENG/O.LML 95.015. ENGS Laboratoire de Géomécanique, Nancy, France.

Kelly, D. Peck, D.C., and James, R.S. 1993. Petrography of granitic samples form the $420 \mathrm{~m}$ Level of the Underground Research Laboratory, Pinawa, Manitoba. Contractor's report to AECL Research. Laurentian University, Sudbury, Ontario.

LAJTAI, E.Z. 1988. The deformation, fracture and strength of Lac du Bonnet granite. Research Report 19. Geological Engineering Deptartment, University of Manitoba, Winnipeg, MB.

MARTIN, C.D. 1993. The strength of massive Lac du Bonnet granite around underground openings. PhD thesis, Department of Civil and Geological Engineering, University of Manitoba, Winnipeg, MB.

MARTIN, C.D. and ChandLer, N.A. 1994. The progressive fracture of Lac du Bonnet granite. International Journal of Rock Mechanics and Mining Sciences and Geomechanics Abstracts, vol. 31, no. 6. pp. 643-659.

Martin, C.D. and Stimpson, B. 1994. The effect of sample disturbance on laboratory properties of Lac du Bonnet granite. Canadian Geotechnical Journal, vol. 31, no. 5. pp. 692-702.

PoLLock, A.A. 2012. AE signal features: energy, signal strength, absolute energy and RMS. acoustic emission tech notes. Technical report TN-10322-9/11. Mistras Group Inc., Princeton Junction, NJ

QueY, R. DAWSon, P.R., and BARBE, F. 2011. Large-scale 3D random polycrystals for the finite element method: generation, meshing and remeshing. Computer Methods in Applied Mechanics and Engineering, vol. 200, no. 17. pp. 1729-1745.

READ, R.S. 1994. Interpreting excavation induced displacements around a tunnel in highly stressed granite. $\mathrm{PhD}$ thesis, University of Manitoba, Winnipeg, MB.

WiLKINS, B.J.S. 1980. Slow crack growth and delayed failure of granite. International Journal of Rock Mechanics and Mining Sciences and Geomechanics Abstracts, vol. 17. pp. 365-369. 